\title{
The Effect of Nutrition Education on Nutritional Status of Tuberculosis Patients
}

\author{
Maria Aslam ${ }^{1}$, Mahpara Safdar ${ }^{2}$, Sidra Khalid ${ }^{1 *}$, Zainab Sharmeen ${ }^{1}$, Tabeen $\operatorname{Irfan}^{1}$ and Kinza \\ Seher ${ }^{1}$ \\ ${ }^{1}$ University institute of Diet and nutritional Sciences, Faculty of Allied Health Sciences, The University of Lahore, Pakistan \\ ${ }^{2}$ Department of Home and Health sciences, Allama Iqbal Open University AIOU, Pakistan
}

*Corresponding author: Sidra Khalid, University institute of Diet and nutritional Sciences, Faculty of Allied Health Sciences, The University of Lahore, Pakistan

\section{ARTICLE INFO}

Received: 慧 December 31, 2020

Published: 㓞 January 25, 2021

Citation: Maria Aslam, Mahpara Safdar Sidra Khalid, Zainab Sharmeen, Tabeen Irfan, Kinza Saher. The Effect of Nutrition Education on Nutritional Status of Tuberculosis Patients. Biomed J Sci \& Tech Res 33(3)-2021. BJSTR. MS.ID.005391.

Keywords: Tuberculosis; Nutrition Education; Nutritional Status; ESR; Hemoglobin Level

\begin{abstract}
Tuberculosis (TB) is a major global health problem and is related to poverty, under nutrition and poor immune function. The nutrition education provides guidance on the nutritional care and support for patients with tuberculosis. Current study was aimed to investigate the effect of nutrition education on nutritional status of tuberculosis patients. This was a pre and post interventional study conducted at Gulab Devi Chest hospital Lahore during December 2016 to February, 2017 among 100 patients of pulmonary tuberculosis. Data were collected by filling questionnaire through interview technique to get an insight into on patients' demographics, lifestyle factors and dietary behavior. Patients were counseled about recommended serving of five food groups and role of nutrition in managing disease and thereby improving nutritional status. Data were analyzed using the SPSS version 21.0. Results revealed that 32\% males, 35\% females were undernourished in pretesting and after three months improvement in BMI occurred i.e. $16 \%$ males, $22 \%$ females in post testing. Level of significance $p=0.013$ increased to $p=$ 0.016 . The nutritional knowledge, Hemoglobin ( $\mathrm{Hb}$ ) and erythrocyte sedimentation rate (ESR) of patients improved significantly after three months of intervention $(p=0.000)$. Most of the tuberculosis patients were undernourished and the threat of TB is affected by the nutritional status. Nutrition education had vital role in diagnosis, management and recovery from TB.
\end{abstract}

\section{Introduction}

Most prevalent deadly contagious disease Tuberculosis (TB) is resulted due to an acid-fast bacterium Mycobacterium tuberculosis [1]. In Pakistan TB is among the basic reasons of morbidity and mortality [2]. Malnutrition and TB are two complications that are connected with each other, presence of one accelerates the other; and the vicious cycle influences individuals towards the expression of clinical symptoms [3]. There is an association between pulmonary TB and malnutrition in patients having co morbidity as diabetes mellitus [4]. Cell-mediated immunity is influenced by under nutrition that is the chief defensive mechanism aligned with TB [5]. Under nutrition is linked with TB infection progression to active morbid state thereby enhancing disease susceptibility and mortality [6]. Deprived nutritional grade is notorious to conquer cellular immunity [7]. To treat and prevent under nutrition, dietary intervention is very important [8]. Nutrient dense diet is recommended to ameliorate poor nutritional status and hence to prevent oxidative stress and further complication in pulmonary tuberculosis patients [9]. A caloric dense diet, high proteins and fats, rich in micronutrients was generally well thought-out to be an important factor in management of the disease [3]. Vegetables and fruits are considered as fundamental constituents of a nutritious meal because of their little calorie count and affluent origins of fiber, micronutrients moreover further huge amount of bioactive compounds enclosing possible consequences on general wellbeing [10]. Micronutrients such as vitamins are linked with nutrition and immunity. 
Furthermore, vitamin insufficiency might influence host resistance for a variety of communicable diseases, together with tuberculosis. Even though tuberculosis sufferers habitually have vitamin D insufficiency, little is acknowledged about the levels of further vitamins as E and B complex [11]. Deficiencies of vitamins and minerals deregulate the immune system accompanied with poor diagnosis and infections susceptibility. Outcome of infectious diseases like tuberculosis are linked with micronutrient deficiencies in the developing countries and contribute towards high disease burden [12]. in both developed and underdeveloped countries under nutrition and poverty are underlying causes of Tuberculosis. Lower risk of active pulmonary tuberculosis is associated with obesity. Risks of developing active tuberculosis is less in overweight and obese persons as compared to normal-weight persons [13].

Numerous literature has elaborated that dietary habits and the inadequacy of nutrition, weight and awareness of wellbeing, body mass index nutrition and nutritional status influence the hazard of TB. Eating practice and predilection of food is one of the hazard features that put in to its expansion. The outcome demonstrated that the wellbeing realization and nutrition between victims were ranged between medium and low. It might be owing to the degree of literacy, which demands added programs of nutrition learning and healthiness regarding contagious illnesses and procedure of avoidance of them, and nutrients sources, antioxidants and significance of food and handling [14]. Pulmonary tuberculosis is a chronic infectious disease which affects nutritional status of the patients. BMI is the biomarker to assess the nutritional status of patient as it also accounts height not just weight. BMI is deliberated by a person's body weight in Kgs divided by the height in meter square $(\mathrm{Kg} / \mathrm{m} 2)$ [9]. The aim of this study was to improve the health outcomes for people with tuberculosis, through improved nutritional care and support.

\section{Methods}

In this before and after (Pre-Post) interventional study, the selected population was studied twice i.e. before and after intervention of nutrition education. Purposive sampling procedure was opted. A sample of 100 patients diagnosed with pulmonary TB was selected from in-door unit of Gulab Devi Chest Hospital, Lahore. After informed consent data were collected from December, 2016 to February, 2017. Allama Iqbal Open University's Institutional Review Board reviewed and approved this study. The study was conducted in three phases, baseline data, intervention and reassessment, individualized diet plan and total six sessions of educational lectures related to nutrition were given to each patient at $1^{\text {st }}, 3^{\text {rd }}, 5^{\text {th }}$, $7^{\text {th }}, 9^{\text {th }}$ and $11^{\text {th }}$ week. A self-structured (pre-tested) questionnaire was used to get an insight into on patients' demographics, lifestyle factors and dietary behavior. Anthropometric measurements of patients were measured in light clothing using stadiometer. BMI, was deliberated by individual's body weight in Kg divided by the height in meter square $(\mathrm{Kg} / \mathrm{m} 2)$. Complete Blood Count (CBC) test was conducted to examine the haemoglobin and Erythrocyte Sedimentation Rate (ESR) levels of the patients. Food frequency checklist was used to evaluate the dietary habits of the patients. The majority of respondents were not able to read and write so the counseling sessions were comprised of verbal discussions in Urdu language. Individualized diet plans were given to patients according to their nutritional requirement. After 12 weeks, patients were again assessed. Patients were interviewed again to assess their improvement in dietary behavior. Anthropometric and biochemical tests were taken to assess the result of intervention. SPSS version 21.0 was used for the analysis of data gained. After running descriptive and cross-tabs t-test was applied. Data appeared skewed so a non-parametric test, the Wilcoxon and Friedman Rank test was run for significance. Level of significance was taken as pvalue $<0.05$.

\section{Results}

It was noted that weight $(\mathrm{Kg})$ of TB patient improved significantly after 3 months of intervention ( $\mathrm{p}=0.000)$. Mean weight (Kg) before intervention was found $47.80 \pm 1.23$ while after intervention mean weight $(\mathrm{Kg})$ increased to $50.27 \pm 1.27$. The results indicated that the BMI of TB patients improved significantly after 3 months of intervention $(\mathrm{p}=0.00)$. Mean BMI before intervention was found $1.76 \pm 0.13$ while after intervention mean BMI increased to 2.30 \pm 0.12 . The Erythrocyte Sedimentation Rate (ESR) in TB patients improved significantly after 3 months of dietary modification $(\mathrm{p}=$ 0.000). Mean ESR level before intervention were found $59.50 \pm$ 2.37 while after intervention mean ESR level were decreased to $45.93 \pm 1.89$ with a mean decrease of 13.57 whereas $p=0.000$. The hemoglobin levels in TB patients improved significantly after 3 months of intervention ( $p=0.000)$. Mean hemoglobin level before intervention was found $11.14 \pm 0.19$ while after intervention mean $\mathrm{Hb}$ level raised to $11.77 \pm 0.13$ with a mean increase of -0.63 (Table 1 \& Figure 1). Body mass index as an indicator of nutritional status has remarkably increased after three months of intervention. There was found significant associations of BMI categories with gender, before and after the intervention. 32\% males, 35\% females were undernourished in pretesting and after three months improvement in BMI occurred i.e. $16 \%$ males, $22 \%$ females in post testing. Level of significance $p=0.013$ increased to $p=0.016$ (Table 2). Dietary intake had significant effect on overall nutritional status of tuberculosis patients. It was evident that consumption of food groups had remarkable effect on BMI, Hb and ESR levels of patients ( $p$ value $=0.001 \mathrm{~s}$ ). There was a significant association between significant as $\mathrm{p}$ value is less than 0.05. Nutrition Education has positive effect. Patients should be counseled throughout the treatment about importance of adequate intake of foods such as milk and milk products, meat and meat products, bread and cereals, fruits and vegetables respectively. Fats and oils group should be used sparingly (Table 3). 
Table 1: Mean nutritional parameters of tuberculosis patients.

\begin{tabular}{|c|c|c|}
\hline Nutritional Parameters & Mean \pm S.D & P-Value \\
\hline $\begin{array}{c}\text { Weight }(\mathrm{Kg}) \\
\text { Pre intervention } \\
\text { Post intervention }\end{array}$ & $\begin{array}{l}47.80 \pm 12.34 \\
50.27 \pm 12.73\end{array}$ & 0.000 \\
\hline $\begin{array}{c}\text { BMI } \\
\text { Pre intervention } \\
\text { Post intervention }\end{array}$ & $\begin{array}{l}1.76 \pm 1.35 \\
2.30 \pm 1.25\end{array}$ & 0.000 \\
\hline $\begin{array}{l}\text { Hemoglobin level } \\
\text { Pre intervention } \\
\text { Post intervention }\end{array}$ & $\begin{array}{l}11.14 \pm 1.94 \\
11.77 \pm 1.38\end{array}$ & 0.000 \\
\hline $\begin{array}{c}\text { ESR } \\
\text { Pre intervention } \\
\text { Post intervention }\end{array}$ & $\begin{array}{l}59.50 \pm 23.72 \\
45.93 \pm 18.94\end{array}$ & 0.000 \\
\hline
\end{tabular}

Table 2: Association of Body Mass Index with Gender.

\begin{tabular}{|c|c|c|c|c|}
\hline \multirow{3}{*}{$\begin{array}{c}\text { BMI } \\
\text { Categories }\end{array}$} & \multicolumn{4}{|c|}{ Assessment Stage } \\
\hline & \multicolumn{2}{|c|}{ Pre intervention } & \multicolumn{2}{|c|}{ Post intervention } \\
\hline & Male & Female & Male & Female \\
\hline Severe Thinness & 16 & 15 & 8 & 10 \\
\hline Moderate Thinness & 0 & 4 & 4 & 1 \\
\hline Mild Thinness & 16 & 16 & 4 & 11 \\
\hline Normal & 18 & 6 & 34 & 19 \\
\hline Overweight & 2 & 7 & 2 & 7 \\
\hline$\chi^{2}$ & \multicolumn{2}{|c|}{12.67} & \multicolumn{2}{|c|}{12.17} \\
\hline$P$ - value & \multicolumn{2}{|c|}{0.013} & \multicolumn{2}{|c|}{0.016} \\
\hline
\end{tabular}

Table 3: Association of dietary intake with biomarkers of nutritional status of tuberculosis patients.

\begin{tabular}{|c|c|c|c|c|c|c|}
\hline \multirow[t]{3}{*}{ Food Groups } & \multicolumn{6}{|c|}{ Medical Conditions } \\
\hline & \multicolumn{2}{|c|}{ BMI } & \multicolumn{2}{|c|}{$\mathrm{Hb}$} & \multicolumn{2}{|c|}{ ESR } \\
\hline & $\chi^{2}(\mathrm{df})$ & p-value & $\chi^{2}(\mathrm{df})$ & p-value & $\chi^{2}(\mathrm{df})$ & p-value \\
\hline Bread and Cereals & $124.61(3)$ & 0.001 & $220.05(3)$ & 0.000 & $74.37(3)$ & 0.001 \\
\hline Meat & $105.08(3)$ & 0.001 & $169.68(3)$ & 0.000 & $37.58(3)$ & 0.001 \\
\hline Milk & $97.45(3)$ & 0.001 & $186.48(3)$ & 0.000 & $50.90(3)$ & 0.001 \\
\hline Fruits & $124.19(3)$ & 0.001 & $179.25(3)$ & 0.000 & $99.19(3)$ & 0.001 \\
\hline Vegetables & $69.99(3)$ & 0.001 & $108.02(3)$ & 0.000 & $47.18(3)$ & 0.001 \\
\hline Fats and Oils & $90.03(3)$ & 0.001 & $157.84(3)$ & 0.000 & $28.31(3)$ & 0.001 \\
\hline
\end{tabular}

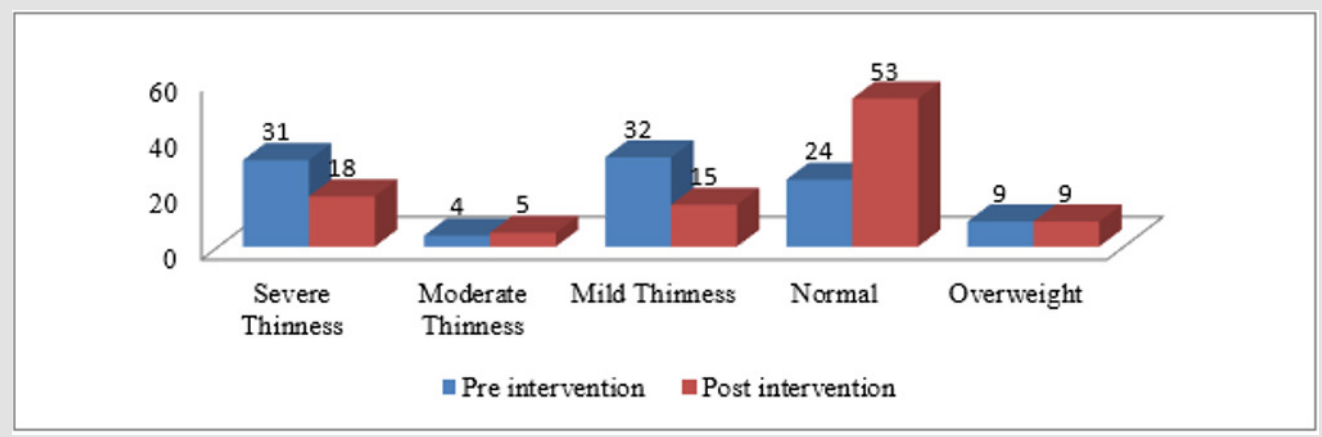

Figure 1: Body Mass Index (BMI) Pre and Post-Intervention. 


\section{Discussion}

Malnutrition commonly prevails in TB, nutritional provision to $\mathrm{TB}$ patients prevents and cure malnutrition; moreover, used to upgrade treatment consequences and as an encouragement to keep patients on treatment. Nutrition counselling is imperative for patients getting dietary support [8]. In the same way, management of malnutrition with the suggested high energy nutritional supplements generates a positive energy balance [15]. In current study dietary intake had significant effect on overall nutritional status of tuberculosis patients. It was evident that consumption of food groups had remarkable effect on BMI, $\mathrm{Hb}$ and ESR levels of patients ( $p$ value $=0.000$ ). In a study by Murimi MW et al. [16] nutritional status of TB patients was evaluated through BMI, $67 \%$ of them were malnourished with BMI less than 18.50 The determination of health related interventions was to improve the wellbeing status of the study population [16]. In current study before intervention, $67 \%$ tuberculosis patients were having BMI less than normal range. Another study informed that, tuberculosis patients were 11 and 7 times more vulnerable for having a BMI $<18.5$ and mid upper-arm circumference (MUAC) $<24 \mathrm{~cm}$, respectively [17]. Casha AR and Scarci M, also reviewed the confirmation among the significant correlation between reactivation of TB and BMI. Which was confirmed with only pulmonary TB and not extra-pulmonary TB, indicating that a less-BMI body build might somehow influence the TB reactivation in the lungs [18]. In current study the ratio of patients with normal and overweight was only 33\%. A study by Yen $\mathrm{Y}$ et al., stated that indicators of BMI overweight and obesity are associated with lesser risk of active tuberculosis progression [19]. BMI of patients have no association with food group consumption. Proper diet and nutrition play significant roles in treating TB patients. As in current study dietary intervention had significant effect on BMI of the patients. In a study by Gurung LM et al., revealed that about one-fifth of TB patients were not consuming adequate amount required to regulate body processes and build and repair tissues and thereby promote health and prevent disease. Micronutrients and macronutrients work together to contribute to tissue regeneration and cellular integrity [20].

\section{Conclusion}

It is concluded that nutrition education has effect on nutritional status of TB patients. Nutrients are required to regulate body processes and build and repair tissues and thereby promote health and prevent disease. Micronutrients and macronutrients work together to contribute to tissue regeneration and cellular integrity. The aim of this study is to help improve the health outcomes for people with tuberculosis, through improved nutritional care and support.

\section{References}

1. Yamshchikov AV, Oladele A, Leonard Jr MK, Blumberg HM, Ziegler TR et al. (2009) Vitamin D as adjunctive therapy in refractory pulmonary tuberculosis: a case report. South Med J 102(6): 649-652.
2. Khan A, Walley J, Newell J, Imdad N (2000) Tuberculosis in Pakistan: socio-cultural constraints and opportunities in treatment. Soci Sci \& Medic 50(2): 247-254.

3. Gupta KB, Gupta R, Atreja A, Verma M, Vishvkarma S (2009) Tuberculosis and nutrition. Lung Indi: official organ of Indian Chest Society 26(1): 9-16.

4. Wang Q, Ma A, Zhao S, Cai J, Zhang Y, et al. (2017) The Impact of Diabetes on Typical Manifestation of Tuberculosis and the Nutritional Status. The FASEB J 31: 789.9.

5. Cegielski J, Mc Murray D (2004) The relationship between malnutrition and tuberculosis: evidence from studies in humans and experimental animals. The Inter J of Tube and Lung Dise 8(3): 286-298.

6. Choi R, Jeong BH, Koh WJ, Lee SY (2017) Recommendations for optimizing tuberculosis treatment: therapeutic drug monitoring, pharmacogenetics, and nutritional status considerations. Anna of Labo Medi 37(2): 97-107.

7. Van Crevel R, Karyadi E, Netea MG, Verhoef H, Nelwan RH, et al. (2002) Decreased plasma leptin concentrations in tuberculosis patients are associated with wasting and inflammation. The J of Clin Endo \& Meta 87(2): 758-763.

8. Mansour O, Masini E, Kim B, Kamene M, Githiomi M, et al. (2018) Impact of a national nutritional support programme on loss to follow-up after tuberculosis diagnosis in Kenya. The Inter J of Tube and Lung Dise 22(6): 649-654.

9. Sultan KM, Alobaidy M, Al-Jubouri A, Naser A, Al-Sabah H (2012) Assessment of body mass index and nutritional status in pulmonary tuberculosis patients. J Fac Med Baghdad 54: 204-208.

10. Bishwajit G, O'Leary DP, Ghosh S, Sanni Y, Shangfeng T, et al. (2017) Association between depression and fruit and vegetable consumption among adults in South Asia. BMC psychiatry 17(1): 15.

11. Oh J, Choi R, Park HD, Lee H, Jeong BH, et al. (2017) Evaluation of vitamin status in patients with pulmonary tuberculosis. J of Infe 74(3): 272-280.

12. Lodha R, Mukherjee A, Singh V, Singh S, Friis H, et al. (2014) Effect of micronutrient supplementation on treatment outcomes in children with intrathoracic tuberculosis: a randomized controlled trial. The Amer J of Clin Nutr 100(5): 1287-1297.

13. Leung CC, Lam TH, Chan WM, Yew WW, Ho KS, et al. (2007) Lower risk of tuberculosis in obesity. Arch of Inte Med 167(12): 1297-1304.

14. Maria A-ZT, Hind A-OS (2012) Food knowledge and preferences of pulmonary tuberculosis patients at Saudi Arabia" A case study". Life Science J-Acta Zhengzhou Univ Over Edit 9: 1089-1099.

15. Evans P, Fatima S (2018) A Good Diet Means Less Medicine-But Is That Enough? J of Ayub Medi Coll Abbot 30(3): 317-319.

16. Murimi MW, Moyeda-Carabaza AF (2017) Effective nutrition education and communication for sustainable maternal and child health. Proc of the Nutr Soci 76(4): 504-515.

17. Shetty N, Shemko M, Vaz M, D’souza G (2006) An epidemiological evaluation of risk factors for tuberculosis in South India: a matched case control study. The Inte J of Tube and Lung Dise 10(1): 80-86.

18. Casha AR, Scarci M (2017) The link between tuberculosis and body mass index. J of Thor Dise 9(3): E301-E303.

19. Yen Y, Hu H, Lee Y, Ku P, Lin I, et al. (2017) Obesity/overweight reduces the risk of active tuberculosis: a nationwide population-based cohort study in Taiwan. Inte J of Obes 41(6): 971-975.

20. Gurung LM, Bhatt LD, Karmacharya I, Yadav DK (2018) Dietary Practice and Nutritional Status of Tuberculosis Patients in Pokhara: A Cross Sectional Study. Fron in Nutr 5: 63 


\section{ISSN: 2574-1241}

DOI: 10.26717/BJSTR.2021.33.005391

Sidra Khalid. Biomed J Sci \& Tech Res

(C) (P) This work is licensed under Creative

Submission Link: https://biomedres.us/submit-manuscript.php

$\begin{array}{ll}\text { BIOMEDICAL } & \text { Assets of Publishing with us } \\ \text { RESEARCHES } & \text { Global archiving of articles } \\ & \text { - Immediate, unrestricted online access } \\ & \text { - Rigorous Peer Review Process } \\ \end{array}$

